partially wanting. So that where one form does not exercise the requisite pressure another should be tried.

Distinct and unmistakable nervous disease may arise in a patient who is the subject of perforate membranes, and with such the diaonosis will be easily made; 'but when the symptoms of what is spoken of as nervous deafness, which would be quite evident in the absence of perforation, are of such a character as to be masked, as it were, by symptoms which are equally present with tympanic disease and disease of the labyriuth, it then requires some additional fact to demonstrate the complicated nature of the affection. By way of illustration, I saw in June last a patient, aged forty-nine, with perforation of both membranes, coming on after scarlet fever at seven years of age. He had had a trifling amount of deafness, which had not given him much inconvenience till six weeks previously. From that time he had been getting gradually more deaf. He was very deaf when I saw him; incessant tinnitus in both ears; the tuning-fork not heard at all through the cranial bones; and occasional attacks of giddiness. Such a case is plain, and no treatment will be necessary. On the other hand, however, the diagnosis at times is somewhat difficult.

Mr. C__-, aged thirty-five, under my care last April, had small-pox at three years of age, followed by discharge from both ears, which had continued more or less ever since. 'The tympanic membrane on the right side was nearly all gone. There was a large kidney-shaped perforation on the left side. He could blow freely through both ears. The watch was heard at eight inches with the right, and four inches with the left, ear; conversation very badly. The discharge was slight; and, after three weeks, had entirely ceased. The hearing was no better. Neither the artificial membrane nor cotton-wool gave any improvement; and yet this case appeared at first sight to differ in no respect from many others in which relief is obtained in this way. The tuningfork was heard perfectly well on the head. No tinnitus or other ordinary unfavourable symptom. It was a suspicious fact that, although the tuning-fork was heard so well through the cranial bones, the sound was not intensified on closure of the meatus. He was quite satisfied on the point after repeated trials both by himself and by me. Still this alone could not be regarded as a sufficient indication of a nervous lesion. There was however this circumstance, which, when taken in conjunction with the previous symptom, was, I think, conclusive-viz., that although the tympana and Eustachian tubes, as far as one could judge, had been in about the same condition for several years past, the hearing had been getting gradually but decidedly worse during the last two years. Without this feature in the case, it would be very difficult to explain why he was not benefited by treatment which might reasonably have been expected to improve the hearing, if the conducting apparatus had alone been at fault.

When the disease appears to be tympanic, but when after treatment the condition of the lining membrane of the tympanum and Eustachian tube has become satisfactory, without a corresponding change in the hearing, and when the artificial membrane or cotton-wool has no effect, I cannot but think that, if the history and symptoms be carefully investigated, there will generally be found a sufficient explanation in the coexistence of a nervous affection with the perforation and tympanic disease; and, in coneluding this part of the subject, I would urge the importance of recognising this condition, as it is only by so doing that those cases which admit of treatment, and those which do not, can be properly separated.

Up to this point the cases under notice have been those in which the Eustachian tube has been not only pervious, but where any obstruction existed it was to so slight an extent that it was without difficulty overcome by using Politzer's inflation. Such is by no means always the case. Occasionally, although some air may pass through the tympanum by this plan, the tube is not sufficiently free to admit the passage of fluids from the meatus. So long, however, as air will pass at all, this condition will be relieved by inflation with the Eustacbian catheter, and by injecting occasionally through it a little warm solution of soda into the tympanum. After this has been practised for some little time, the other plan of injection from the meatus will be found to be quite practicable, and until this can be done (in the manner explained in my previous paper), a successful result is, I believe, extremely improbable. The not very frequent, though serious, complication in tympanic disease which has resulted in perforation of the membrane-riz. complete occlusion of the Eustachian tube-I must leave for consideration with some other effects of this condition. Sackville-strect, August, 1870.

\section{FATAL CASE OF RUPTURE OF BLADDER, IN WHICH THE-APERTURE HAD BEEN CLOSED BY OMENTUM AND BOWEL.}

\section{Bx THOMAS D. JONES, M.R.C.S.E., L.S.A.}

THI following case, one of traumatic rupture of the bladder, is, I think, somewhat worthy of note from its possessing several peculiarities, one of which, indeed, is probably extremely rare. In ordinary rupture of the bladder involving the peritoneum, one would anticipate extravasation and acute peritonitis. In this case there was scarcely any, the aperture in the bladder having been completely sealed up by omentum and the sigmoid flexure.

F. B - aged fifty-five, was, on June 6th, riding a horse, which reared, lost its balance, and fell backwards, the rider clinging to the saddle, and receiving the entire weight of the horse, the pummel of the saddle striking him on and above the pubes. He lay prostrate, and was momentarily stunned. On seeing him, immediately after the accident, I found him in a state of great collapse, on recovering from which he complained of intense pain in the region of the bladder. Suspecting rupture of that viscus, and as he had been taking a large quantity of fluid, I introduced a catheter, and drew off about three ounces of bloody urine; gave forty minims of tincture of opium. When removed to bed he was seen by $\mathrm{Mr}$. Willett and myself. Complained of great pain in the hypogastric region, more especially on the left side, which be described as travelling upwards. To have hot fomentations constantly to abdomen, and half-drachm doses of tincture of opium every two hours.

Five hours afterwards.- Has slept nearly the whole time since last seen. Skin warm; pulse 80 ; respiration natural. Drew off about two drachms of dark-brown urine.

June 7th.-10 A.M. : Has slept well. Has taken searcely anything through the night. Pulse 72, soft and regular; respiration normal. Abdomen sliohtly tympanitic, but quite tolerant of pressure; no sign of bruising. Drew off five ounces of urine without blood. -2 P.M. : Not so well; collapse. Pulse 120. Cold sweats; dusky countenance, and anxious aspect. -5 P.M. : Mr. Quain joined in consultation. To continue opium, beef-tea, and half an ounce of brandy every two hours. Stimulating fomentations.-9.30: Pulse 98 ; feels better. Tympanites increased; no sickness, and no passage of flatus.

8th.-Has had a very restless night. Tympanites very much increased. Belly very tense. At 1 P.M. was sick for the first time; brought up a small quantity of mucus and altered blood. Slight collapse.-9 P.M. : Collapse increasing; no pain; sinking fast. Died at 12.40 A.M.

The autopsy was made fifteen hours after death, in the presence of Mr. Willett. No external marks, no ecchymosis. Abdomen very much distended. The peritoneal cavity contained ten ounces of serous fluid. No signs of active inflammation. Omentum large and fat, natural in appearance, just glued to the intestines; but the lowest portion, to the extent of two fingers' breadth, congested, blood-stained, and thickened, as if it had been subjected to strangulation. The intestines were examined throughout, and found entire; distended and dark-coloured. Stomach contained about four ounces of grumous fluid; very much congested and injected. Duodenum injected, and filled with grumous blood. Small intestines for nearly the whole extent with the same appearance. Descending colon collapsed. The sigmoid flexure lay over the bladder. On pulling away the bowel from the bladder, a rupture was seen about the size of a five-shilling piece; the margin of the rent was coated with lymph, and had evidently been blccked up by the altered piece of omentum and sigmoid flexure of large intestine.

On reviewing the case, I may state that the opinion formed at first was, that xupture of the bladder had oc. 
curred. This opinion we were inclined to modify on the following day on these grounds-rapid recovery from collapse and normal urine. Subsequently the symptoms pointed more to a rupture of intestine. The post-mortem examination verifed our first opinion; and one may now account for the absence of the ordinary symptoms of rupture of the bladder on the ground that the laceration had been sealed immediately by the omentum, which had slipped into it.

York-place, Islington-green, N., July $27 \mathrm{th}, 1870$.

\section{CASE OF SEVERE DISLOCATION OF BOTH TIBIA AND PATELLA OUTWARDS.}

\author{
BY RICHARD NEALE, M.D. LoND., \&c.
}

ON May 11th, 1870, at 9 P.M., I was called to Mr. H(height, 5 ft. $10 \frac{3}{4}$ in.; weight, $14 \frac{1}{2}$ st.), who had met with a severe accident. The following written statement was handed to me at the bedside:- " $\mathrm{Mr}$. $\mathrm{H}$ _— was brought in here to-night about 6.30, with a severe dislocation of the left tibia outwards, and also of the patella outwards. I have temporarily applied a slight splint, as the dislocation is very easily reproduced.-W. B. Whitmore, King's College Hospital, May 11th, 1870."

On examination, the limb was found tolerably comfortable, and not much swollen. The patient had borne the journey home very fairly, was cheerful, and exceedingly hopeful as to the result. The bandages were not disturbed; and although the temporary splint was not padded, it gave no pain, and therefore the limb was carefully adjusted on pillows, and he passed a very good night.

On the third day the leg was slung in an ordinary fracture cradle, to the very great comfort of the patient.

On the sixth day the bandages were slightly loosened, but neither they nor the splint were changed; and so matters rested till May 24 th, up to which date the patient scarcely felt an ache or a pain, except being occasionally, for the first few nights; a wakened by sudden startings in the limb.

May 24th.-Mr. Spencer Wells saw the case previous to edjusting a plaster bandage. On removing the splint and bandages applied on the 11th, a very slight excoriation was found at one spot, due to pressure of edge of splint. The knee-joint was in perfect position, and but slightly swollen; gentle motion gave no pain, but naturally the experiment was not carried very far. A plaster-of-Paris bandage was applied, and this was replaced at the end of a week or ten days, after which the patient moved about on crutches.

June 17th.-An elastic laced knee-cap, made by Maddox, was this day applied, since which time up to the present moment there has been daily progress, the patient frequently going into town, and as early as July 22 nd could bend the the knee nearly at right angles without the slightest feeling of diseomfort.

July 28th:-Mr. H— called at King's College Hospital to report himself, and to thank Mr. Whitmore for his care on the evening of May 11th. Sir W. Fergusson was present at the interview, and both were surprised at the state of the limb, more especially as Mr. Whitmore says, in a private letter to myself that the words "very easily reproduced scarcely convey the full extent of the mobility of the joint; and the impression made upon my mind by the accident was so strong that I used all my endearours to persuade the patient to remain in the hospital, apprehending serious consequences from inflammation after the severe ivjury.",

Sir Wm. Fergusson at the same time told Mr. H- that he might consider himself a very lucky fellow, for it was a wonderful recovery after so severe and unusual an accident, it being the most severe case of dislocation the house-surgeon had seen, and that it was quite a chance the leg had not been sacrificed altogether.

As far as Mr. H- can recollect, the accident occurred as follows:- "I was hurrying down Holborn, the rain falling fast, which it had done all day, when $m y$ foot slipped, and I made a desperate plunge with the other to save myself, and fell to the ground. I did not know I had severely injured myself, and made several attempts to get up, but of course friled to do so, and discovered what I thought to be a broken leg, but had no knowledge of great pain. I called a cab, and desired to be taken to the nearest hospital ; but from this point until I found myself in bed at the hospital I have no distinct idea. I have suffered very little pain throughout; the swing cradle has been my greatest comfort, and I an to-day (dugust 4th) very well, using an ordinary walking-stick, and walking two or three miles with comfort."

This case is recorded, not on account of any special treatment, but as an instance of the great restorative powers of nature where at one time there appeared great danger that the limb would be sacrificed, or at least permanently stiff. The great patience and good constitution of the patient contributed not a little to toe successful issue.

Boundary-road, St. John's-wood, A ugust, 1870.

\section{a a thitror}

OF THE PRACTICE OF

\section{MEDICINE AND SURGERY IN THE}

\section{HOSPITALS OF LONDON.}

Nulla autem est alia pro certo noscendi via, nisi quamplurimas et morborum et dissectionum historias, tum aliorum, tum proprias collectas habere, et inter se comparare.-Morga

\section{UNIVERSITY COLLEGE HOSPITAL.}

CASE OF POPLITEAL ANEURISM WHICH RESISTED FOR THREE MONTHS COMPRESSION BY INSTRUMENT, WEIGHT, FINGER, AND FLEXION ; LIGATURE OF SUPERFICIAL FEMORAL ; RECURRENT PULSATION ; CURE.

(Under the care of Mr. Erichsen.)

THe following interesting case of popliteal aneurism resisting every method of treatment by compression was admitted April 4th.

J. S- aged thirty, was a sailor for ten years, but during the last six years has been a cab-driver. Has been a remarkably healthy man; never had any serious illness. Had a sore on his penis about eight years ago, which rapidly healed; no eruption appeared on his body. Has been liable to sore-throat since. There is multiple enlargement of the glands in both groins. His wife has had three miscarriages has two children living, both healthy. His father died suddenly of heart disease; brothers and sisters died young

Two months ago he felt a continual gnawing pain in the right ham, increased during cold weather. A month after this, feeling something strange in the bend of the knee, he measured the limbs, and found the right measured three quarters of an inch more than the left. The pain was greatly diminished by warm weather, and on raising the $\operatorname{limb}$.

Present state.-There is a popliteal aneurism, about the size of a small orange, in the middle of the right ham; a distinct bruit is heard over it, and the pulsation ceases on compressing the artery above. Mr. Erichsen ordered Carte's tourniquet to be applied to the external iliac and femoral, pressure to be kept up by these alternately, the limb to be bandaged and kept slightly raised, and the patient to be put upon the following diet:-Meat, three ounces morning and night ; bread, four ounces; milk, a pint; watercresses and ice.

Compression was commenced on April 5th. As the patient did not bear the pressure well, forty grains of chloral were given at 9 P.M., and repeated at midnight. This did not have much effect, and compression was continued during the night with difficulty, owing to the restlessness of the patient. The same doses of chloral were given the following night, the patient sleeping well, and the artery being well compressed, so as to control all pulsation in the aneurism.

April 7th. - The patient continued to be restless, was very nervous, and difficult to manage. The compressors were, therefore, removed, and digital compression most carefully and assiduously kept up by relays of dressers for twelve hours. The tournignets were then readjusted, and, under the influence of chloral, pressure was steadily 